\title{
CONTROL OF PAIN DURING LABOUR ${ }^{\circ}$
}

\author{
HENRY J. SHYKofr, M.D. ${ }^{\dagger}$
}

Too ofren, before she even meets the anaesthetist, the woman in labour has already experienced the greatest part of the pain associated with having her baby. She then receives an epidural block, a saddle block, or other form of anaesthetic for the final half hour or so of labour. The first stage is often a trying, unpleasant, and painful episode. In the past this has been dealt with relatively inadequately by the use of powerful depressants such as narcotics and ataractics, drugs which often do little good for the mother and some harm to the baby.

Although it has been known for more than forty years that a lumbar sympathetic block of T-10 to L-1 will result in painless uterine contractions, little has been done to take advantage of this fact to relieve the pain of the first stage of labour. Many techniques have appeared to block the outflow from T-10 to L-1: superior hypogastric plexus injection, bilateral T-11 to T-12 nerve root blockade, paravertebral blockade by either continuous or single injection, continuous caudal analgesia, continuous epidural anaesthesia, and the presently very popular paracervical block. In our efforts to provide first stage analgesia, we have found the injection of dilute, long-acting local anaesthetics in the lumbar epidural space, preferably by the continuous catheter technique, to be a most satisfactory method not only for maternal comfort but also for foetal and maternal safety. This paper describes the evolution of this method.

\section{Physiologic and Anatomic Consmerattons}

There are two types of pain associated with labour:

1 . Visceral pain caused by uterine contraction and the dilatation and effacement of the cervix.

2. Somatic pain associated with vaginal stretching and direct pressure on the bony pelvis.

\section{Visceral pain}

The mechanism of uterine pain is still poorly understood. Some physiologists think that the pain is due to acidosis resulting from the anaerobic metabolism in uterine muscle, accompanying hypoxia caused by reduced blood flow during prolonged contractions. A similar phenomenon occurs during stretching of the cervical os. The painful sensation, whatever its cause, is transmitted by uterine afferent nerves. These are visceral afferent " $\mathrm{C}$ " fibres. They range from 1.3 to .2 microns in diameter and transmit sensation at the rate of .6 to $2.3 \mathrm{~m} / \mathrm{sec}$, the so-called slow pain component. These afferent fibres from the uterus lie along

'Presented at the Annual Meeting, Canadian Anaesthetists' Society, May 13-16, 1968.

tDepartment of Anaesthesia, Toronto East General and Orthopaedic Hospital. 
the course of the corresponding sympathetic nerves, and enter the spinal cord at levels T-11 to L- 1 via the dorsal roots. Thus blocking the appropriate sympathetic fibres will block uterine afferents.

\section{Somatic pain}

The uterus has no somatic sensory fibres, but the vagina and pelvic periosteum are richly supplied. Pain emanating from these sources is due to direct stimulation of sensory somatic or "A $\delta$ " fibres. These fibres become part of the sacral and lower lumbar sensory nerves, are of relatively large size (3 to 6 microns) and transmit sensation quickly, at the rate of greater than $20 \mathrm{~m} / \mathrm{sec}$, the so-called fast pain component.

Blocking the visceral afferent " $\mathrm{C}$ " fibres, then, will abolish all uterine pain, but it does not block the pain of extra-uterine origin. The latter is encountered with malpositions and is presumed to be due to persistent pressure on bony structures. " $\mathrm{C}$ " fibres are very small in diameter and have a large surface/volume ratio. Therefore they require few molecules of local anaesthetic agent to effect a block. The large ( 3 to 6 micron) sensory fibres have a smaller surface/volume ratio, and require more molecules of local anaesthetic agent to effect a block.

The usual pain of the first stage of labour is uterine, transmitted by "C" fibres. Sometimes labour is complicated by the additional pain of malposition, "A $\delta$ " fibres. Therefore we may require two different types of block. The method of analgesia to be described copes with this problem and provides a means of making labour reasonably comfortable.

It has been difficult to find many references to complications following the use of epidural anaesthesia or the use of the continuous technique employing catheters. In the earlier years the tubing was brittle and sometimes broke at the skin level, ${ }^{1}$ but there have been no reports of this nature with the tubing available at present. Bromage advises against the use of epidural catheters in patients on anticoagulant therapy, ${ }^{2}$ and this has been confirmed in a recent case report. ${ }^{3}$ The extremely low incidence of infection following epidural block may be related to the antibacterial action of the local anaesthetic agents. ${ }^{4}$

Ideally, a drug used for the control of pain in labour should have the following properties: It should provide complete pain relief, should have no action on the foetus, and should not be toxic. There should be no adverse effects on the course of normal labour. It should be active throughout the first stage. Maternal physiology must remain unaltered, and the drug should be one that can be easily administered.

A block of small sensory fibres is all that is required to provide analgesia through the normal first stage of labour. Because these nerves travel for part of their route with the sympathetic supply to the uterus, sympathetic block of T-10 to L-1 will provide this analgesia. The epidural space is an easy route of access to these sensory fibres and so we have used this approach.

The block is performed in the usual manner using "loss of resistance" as the indicator to the space. Fifteen cubic centimetres of the drug to be used is injected. The patient is positioned on her back. Blood pressure and foetal heart are checked 
at five-minute intervals for fifteen minutes, at which time the drug is assumed to be fixed. Knee, ankle, and plantar reflexes are checked and noted.

The block is performed at any time after labour is established, usually when the patient is distressed by her contractions.

The following drugs were used in this order:

1. Lidocaine (Xylocaine) 0.5 per cent with epinephrine 1:400,000.

2. Lidocaine 0.75 per cent with epinephrine 1:300,000.

3. Lidocaine 1 per cent with epinephrine 1:200,000 (all dilutions of Lidocaine 2 per cent with epinephrine 1:100,000).

4. Tetracaine (Pontocaine) 0.1 per cent with epinephrine 1:200,000.

5. Dibucaine (Nupercaine) 1:1500 with epinephrine 1:200,000.

When 0.5 per cent Lidocaine was used, we obtained the following results:

1. Good pain relief.

2. No apparent action on the foetus.

3. No evidence of toxicity.

4. No adverse effects on the course of normal labour (excellent bearing down).

5. Short duration of action (less than two hours in all cases).

6. Some numbness and weakness of legs. Reflexes absent in most cases. Most patients could not void.

7. Because of the short duration of this drug, either repeated epidural taps or repeated blocks through an epidural catheter were required.

Because of the short duration of action of lidocaine 0.5 per cent more concentrated solutions were used. But there was little, if any, prolongation of duration of action, and there was greatly altered maternal physiology. The patients were in most cases anaesthetized. We lost more than we gained.

Tetracaine 0.1 per cent with epinephrine was used in 16 patients. This gave us a visceral afferent block accompanied by only slight sensory changes. The results may be summarized as follows:

1. Good pain relief in normal cases.

2. No apparent action on the foetus.

3. No evidence of toxicity.

4. Expulsive efforts were good. However, five of the sixteen patients reported annoying sensations in their legs which they could not describe, but which were very distressing. Reflexes were equivocal. Some of the patients could void, others could not.

5. Duration of action was good, ranging from two to five hours, with most at the upper limit. Eight patients proceeded to full dilatation on the single block and required a second block of xylocaine two per cent with epinephrine only for delivery. The others had to be reblocked once and then again for delivery. There was no perineal anaesthesia with tetracaine.

The remaining and greatest number of patients in this series received dibucaine 1:1500 with epinephrine 1:200,000. Results were as follows:

1. Good pain relief in normal labours.

2. No apparent action on the foetus.

3. No evidence of toxicity. 
4. Expulsive efforts were good, but as with tetracaine, no perineal analgesia was present.

5. Long action. One block took most of the patients through to full dilatation. Duration of action in some was in excess of six hours. (See Fig. 1).

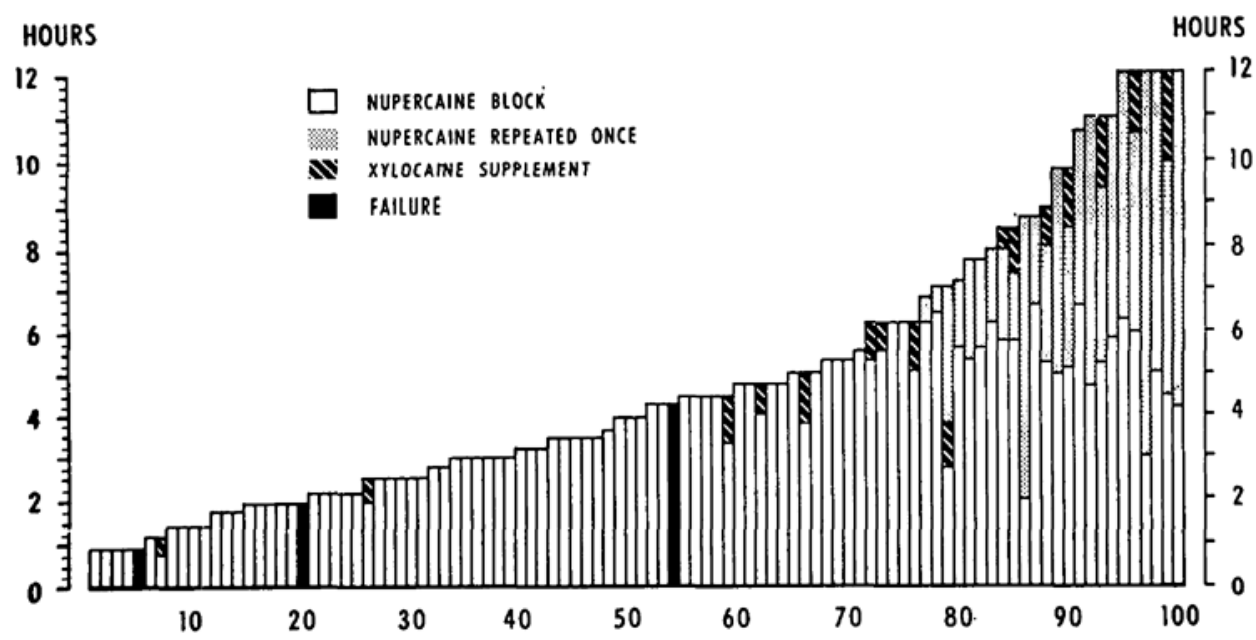

Fucure 1. Duration of labour following induction of epidural block with dibucaine (Nupercaine) $1: 1500$ with epinephrine $1: 200,000$ in the first 100 cases in the series reported. Repetition of the block or supplementation is indicated in each case.

6. There were no alterations in skin sensation. Motor power appeared to be normal. No unpleasant effects noticed. Blood pressure very stable. The patients could sit up and could walk with assistance. Most could void with no difficulty.

There are disadvantages inherent in these procedures. In multipara experiencing normal labour there was no warning of impending full dilatation; consequently some labours ended precipitantly. Patients with malpositions and relative or absolute disproportions often experienced backache, and sometimes pain in the thighs and lower abdomen. Neither the tetracaine nor the dibucaine blocks controlled these pains, nor did lidocaine 0.5 per cent, and a narcotic was sometimes required. Lidocaine in concentrations greater than 0.5 per cent eliminated these pains but the patients had excessive muscle weakness and a drop in blood pressure with change in position, and they required frequent blocks. Some exhibited tachyphylaxis in prolonged labour. All these patients required an additional lumbar epidural block for delivery.

Because dibucaine 1:1500 most closely approached our criteria for the ideal agent, its use was continued. In order to overcome most other disadvantages, an epidural catheter was implanted at the time of initial block. In normal primipara, when the cervix was fully dilated, the patient was asked to sit up in bed and $3 \mathrm{cc}$ of lidocaine 2 per cent with epinephrine was injected through the catheter. The pain of bearing down was thereby removed to a great degree. When the presenting part was on the perineum, a further $15 \mathrm{cc}$ of lidocaine was given, and 
the patient was transferred to the delivery table. This anaesthesia was adequate for all vaginal deliveries.

The multiparous patient, when fully dilated, is also asked to sit up and $15 \mathrm{cc}$ of 2 per cent lidocaine with epinephrine is run down through the catheter. Because the anaesthetic is low, she can be delivered either under her own power or with outlet forceps.

The pain experienced with a malposition can be readily controlled by the addition of $3 \mathrm{cc}$ of 2 per cent lidocaine into the catheter with the head of the bed elevated.

When a "trial of labour" has failed, the anaesthetist only has to add $20 \mathrm{cc}$ of lidocaine 2 per cent with epinephrine as the sole anaesthetic for the Caesarean section.

The method described above differs from a conventional continuous epidural in that pain is controlled by a small afferent nerve block with very dilute solution. There is no peripheral anaesthesia whatever because only $10 \mathrm{mg}$ of dibucaine is used, and the danger of toxic effects is almost nil because of the small dose. The prolonged effect of dibucaine is a great advantage.

Anaesthetists who do not like to use epidural catheters can give most patients a pain-free labour by using a dibucaine block for the first stage, and their usual anaesthetic for delivery.

Most of our anaesthetists use catheters; some do not. We have experienced no
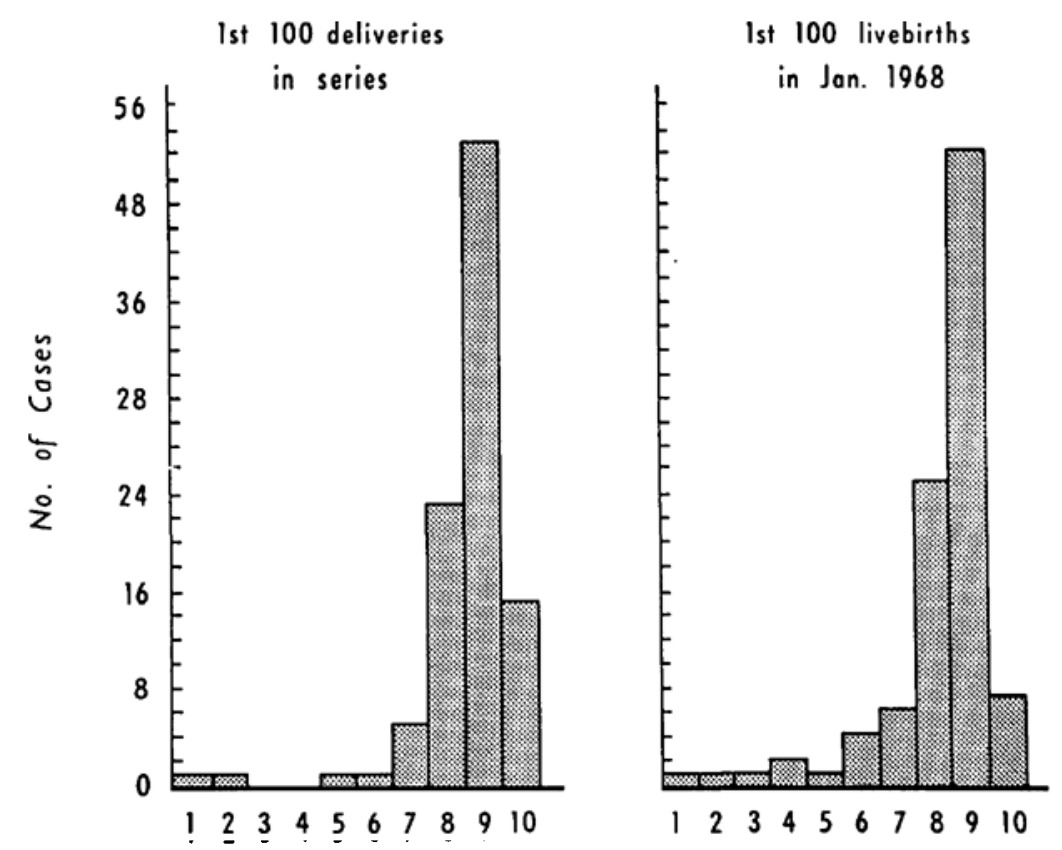

Figure 2. Histograms comparing (left) the Apgar scores of the first 100 deliveries following epidural block with dibucaine for analgesia in the first stage of labour with (right) those for a consecutive series of 100 live births in which other methods of analgesia were employed. 
complications to date. The patients at the beginning of this series were those with somewhat complicated labours. Our primary section rate was 8 per cent. Seven of the eight sections were in the first half of the series. There is still some reluctance on the part of many people doing obstetrics to change their methods of analgesia, but in our hospital the number who make use of our service is increasing rapidly.

Because of very low drug dosage for first-stage analgesia, and the small dosage for delivery, the drug level in the foetal circulation remains low and we have noted no foetal bradycardia. The Apgar ratings have been high (Fig. 2). Recently our obstetricians have been asking for these long-acting epidural blocks where violent labour is associated with foetal distress. It is not easy to explain why the block helps in these cases, but it changes the type of labour to a more normal pattern, and signs of foetal distress usually disappear.

\section{SUMMARY}

An epidural block using dibucaine (Nupercaine) 1:1500 with epinephrine 1:200,000 will give analgesia during labour lasting up to six hours. This is usually long enough to carry most patients through their first stage of labour in comfort with no physiological changes in mother or baby. The mother behaves as if she were in mild easy labour. The foetal heart rate is unaffected. The Apgar rating at delivery is good. Oxytocin-induced contractions are well tolerated. Bearing down is excellent despite some vaginal discomfort, which can be readily controlled if an epidural catheter is used. Only a small dose of anaesthetic agent is needed for delivery, and therefore muscle strength remains good, and forceps are not always necessary.

We have described a programme of obstetrical analgesia resulting in controlled painless labour and delivery with minimal changes in maternal and foetal physiology.

\section{RÉSUMÉ}

Un bloc épidural à l'albucaïne à 1 pour 1,500 associée à l'adrénaline à 1 pour 200,000 , produira durant le travail, une analgésie qui va durer jusqu’à six heures. Ceci est généralement suffisant pour que la plupart des patientes franchissent confortablement le premier stage du travail, sans troubles physiologiques pour la mère ou pour l'enfant. Pour la mère, tout se passe comme si le travail était doux et facile. Le rythme du cœur foetal n'est pas affecté. A la délivrance, l'évaluation d'Apgar est bonne. Les contractions provoquées par l'oxytocine sont bien tolérées. L'expulsion est excellente malgré un certain malaise vaginal, qui peut être contrôlé rapidement si on a mis en place un cathéter épidural. Il ne faut qu'une dose légère d'anesthésique pour la délivrance; en conséquence, la force musculaire demeure bonne, et on n'est pas obligé de toujours recourir aux forceps.

Nous avons décrit une technique d'analgésie obstétricale qui procure un travail et une délivrance sans douleur et sans variation sensible de la physiologie maternelle et foetale. 


\section{REFERENCES}

1. Ostlere, Gordon. Epidural Analgesia in the Treatment of Hypertension Due to Toxaemia of Pregnancy. Anaesthesia. 7: 169 (1952).

2. Bromace, P. Spinal Epidural Analgesia. Edinburgh: E. \& S. Livingstone (1954), p. 101.

3. Gingrich, T. F. Spinal Epidural Hematoma Following Continuous Epidural Anesthesia. Anesthesiology. 29: 162 (1968).

4. Terlow, A. Paper presented to the Seminar on Regional Anesthesia (University of Miami and University of Florida), January 1968. Not yet published. 